\title{
CONTRA DURKHEIM. LA SCIENCE SOCIALE COMME VISION DU MONDE, DE WIKTOR STOCZKOWSKI
}

\author{
Thomas Jacques Cortado ${ }^{1}$
}

${ }^{1}$ Universidade Estadual de Campinas - Unicamp, SP, Brasil

\section{O escândalo Stoczkow ski}

Segundo o sociólogo Matthieu Béra, o último livro de Wiktor Stoczkowski, La science sociale comme vision du monde. Durkheim et le mirage du salut, causou "um efeito de estupefação, ou de nojo, entre alguns especialistas que renunciaram a lê-lo até o fim ou a comentá-lo" (Béra 2019:8). Publicado em 2019, esse estudo volumoso, com mais de 600 páginas e aproximadamente 700 referências bibliográficas, ainda aguarda a reação de outros "durkheimólogos", mas as primeiras resenhas deixam antever seu provável teor. ${ }^{1}$ Embora elogie "uma visão sintética, às vezes original" de Durkheim (:8), Béra acusa Stoczkowski de "ataques ad hominem e falas bastante difamatórias", motivadas por quinze anos de "meditação" e de "ódio" (:8). Já os sociólogos Jérôme Lamy e Arnaud Saint-Martin afirmam que "todo o empreendimento do comentário durkheimológico se [encontra] desestabilizado com essa interpretação dissonante" (2020:493). Para eles, os argumentos de Stoczkowski, entre os quais também detectam "insinuações difamatórias" (:509), estariam repletos de preconceitos, vieses reducionistas e anacronismos. Tratar-se-ia de uma "antropologia de gabinete" (:510), cujo único objetivo seria abalar os pilares das ciências sociais, sem trazer nenhuma alternativa. E Béra ainda conclui: "O Durkheim de Wiktor Stoczkowski não é o nosso. A gente lhe deixa o seu" (2019:9). 
Não é a primeira que Stoczkowski escrutiniza um "grande autor" das ciências sociais. O seu livro anterior, Anthropologies rédemptrices. Le monde selon Lévi-Strauss (2008), pretendia também reconstituir a cosmologia do antropólogo, na época sob os holofotes por completar seu centenário. Professor na École des Hautes Études en Sciences Sociales (EHESS), membro do Laboratoire d'Anthropologie Sociale (LAS), Stoczkowski se especializou no estudo dos saberes científicos, em particular da arqueologia pré-histórica (2000), e pseudocientíficos, tal como a ufologia (1999). Entretanto, todo o trabalho de Stoczkowski tende a relativizar esta distinção. Assim como as pseudociências, as ciências têm raízes em crenças do pensamento ordinário. A figura do homem pré-histórico, por exemplo, não surgiu em ruptura com as conjeturas teológicas e filosóficas dos séculos anteriores, muito pelo contrário: Jacques Boucher de Perthes, "pai fundador" da arqueologia moderna, considerava o homem pré-histórico uma encarnação do "homem antediluviano"; logo, ele retomava a narrativa bíblica de uma descontinuidade essencial na história humana (Stoczkowski 1993).

Stoczkowski ataca, portanto, "o mito da ruptura fundadora com o senso comum" (2015:158), tão decisiva para a escola francesa de epistemologia histórica. Escolhe como alvos principais os chamados "pais fundadores" das ciências sociais, pois desempenham um papel eminente na "hagiografia da ciência, que tenta estabelecer a qualquer custo uma distinção nítida entre crenças e saberes, amplificando a irracionalidade na abordagem daquelas para realçar melhor a suposta racionalidade desses" (1993:14). Desde 2005, no seu seminário da EHESS, investiga as crenças "dissimuladas" (palavra recorrente, e problemática, no vocabulário de Stoczkowski) nas obras de Edward Burnett Tylor, William James, Edward Sapir, Pierre Bourdieu, Bruno Latour, Claude Lévi-Strauss e Émile Durkheim, muitas vezes à revelia das interpretações consagradas. Acredita que essas crenças constituem, "dentro das teorias reputadas científicas, um sistema de esquemas conceituais emprestados à teologia e à filosofia, mas que se tornaram irreconhecíveis devido à longa série de transformações que viveram" (2019:18). Em seu último livro, chama de "anamorfoses conceituais" essas transposições de conceitos.

A principal hipótese de Stoczkowski é que "as ciências sociais produzem visões do mundo análogas às cosmologias estudadas pelos antropólogos nas sociedades não ocidentais" (2019:12). Chama de cosmologia "as representações totalizantes que dizem respeito à forma do mundo, aos seres que ele abriga, às relações entre eles, às leis que os governam e ao lugar do homem neste conjunto" (:29). As cosmologias possuiriam quatro dimensões: uma axiologia (teorias dos valores morais, do bem e do mal), uma ontologia 
(teoria do ser, do essencial e do acidental), uma etiologia (teoria das origens do mal) e uma soteriologia (teoria da salvação). Talvez a maior originalidade de Stoczkowski esteja na importância que atribui a esta última. Segundo ele, "a ambição soteriológica acompanha o trabalho das ciências sociais desde sua fundação até hoje" (:31). Lévi-Strauss, por exemplo, culpava a separação do homem com a natureza e a superpopulação (etiologia) pela destruição das culturas, pelo extermínio de populações e pela devastação do planeta (axiologia). A etnologia tinha por missão reaproximar o homem da natureza, graças ao conhecimento de sociedades que mantinham esse convívio (soteriologia). Temos, muito resumida, nossa cosmologia (Stoczkowski 2008).

Entretanto, há algo mais polêmico na escolha de Durkheim. Certamente, não se trata da primeira vez em que Durkheim recebe críticas, mesmo severas. Com Gabriel Tarde, nunca parou de debater, inclusive para além da morte, graças a Latour (Vargas et al. 2014). Ainda vivo, enfrentou oposições de várias naturezas. O filósofo anarco-sindicalista Georges Sorel (1895) criticou o organicismo de Durkheim, incapaz de compreender a centralidade do conflito social (luta de classes). Tomista, advogado e político católico, Simon Déploige (1911) ironizou sobre a tentativa de Durkheim de criar uma moral com base na sociologia. Outro pensador católico, mais excêntrico, Charles Péguy (1992 [1905]) condenou a sociologia racionalista de Durkheim em nome de um espiritualismo vitalista. Dentro de um registro mais político ainda, Paul Nizan acusou Durkheim de promover uma sociologia conservadora, feita para ensinar às crianças "a respeitar a Pátria francesa, a justificar a colaboração de classes, a aceitar tudo, a comungar no culto da Bandeira e da Democracia burguesa" (1965 [1932]:110).

A estas críticas se somaram outras, como a do fenomenólogo comunista e próximo dos surrealistas Jules Monnerot, que publicou, em 1946, Les Faits sociaux ne sont pas des choses. Enquanto a sociologia estava em processo de (re)institucionalização na França, Jean Piaget chamou de "realismo totalitário" o tipo de explicação promovida por Durkheim (1955:145), ao mesmo tempo em que Raymond Aron (1967), que nunca escondeu sua antipatia pelo diretor da Année sociologique, fazia um balanço nada favorável de sua obra. Se Stoczkowski menciona objeções voltadas para determinadas partes da obra de Durkheim, como sua sociologia do suicídio e sua teoria da religião, é uma pena ele não situar o seu trabalho no conjunto dessas críticas sistemáticas, pois dá a falsa impressão de que se trata de um gênero novo.

A favor de Stoczkowski, temos que reconhecer o pouco espaço concedido às críticas de Durkheim nas apresentações mais didáticas do sociólogo francês. Prevalece nos manuais destinados ao ensino médio e aos estudantes de primeiro ciclo universitário uma representação heroica 
de Durkheim, gênio que soube tirar a sociologia de seu sono dogmático e lhe conferir sua necessária e legítima autonomia, ao travar uma batalha intelectual e institucional com os psicólogos e os filósofos (Béra 2014a). Eu mesmo, enquanto estudava ciências sociais no ensino médio, sequer ouvi falar de Tarde; como único contraditor de Durkheim, devido à sua defesa do holismo, tínhamos Max Weber, suposto promotor do individualismo metodológico, mesmo que nunca tivesse escrito uma linha a respeito do sociólogo francês. ${ }^{2}$ Por ter sido lançado pela Nouvelle Revue Française (NRF, Gallimard), uma coleção prestigiosa, mas generalista, acredito que o público visado por Stoczkowski em La Science sociale comme vision du monde inclui não apenas os durkheimólogos, mas todas as pessoas interessadas pela obra do chamado "pai fundador".

Como explicar então as primeiras reações dos durkheimólogos? A despeito das críticas já feitas, nunca se põe em xeque o caráter científico da obra de Durkheim. Havia divergências quanto à ciência que se devia praticar e oposições às conclusões práticas que se tiravam dela, não suspeitas acerca das intenções que a animavam. Stoczkowski pinta Durkheim como um ideólogo escondido em roupas de cientista. "Descobri surpreso que Durkheim tinha fundado sua obra em cima de uma base factual muito modesta, que sua erudição era muitas vezes cismada, que ele maltratava sistematicamente os dados, que não o incomodava recorrer a paralogismos, que não hesitava em manipular seus leitores com artifícios retóricos", lança Stoczkowski nas primeiras páginas de sua introdução (2019:19). Enquanto seu penúltimo livro focava em dois textos apologéticos de Lévi-Strauss, Race et histoire, de 1952, e Race et Culture, de 1971, Stoczkowski pretende demonstrar a influência da cosmologia de Durkheim até no seu trabalho científico, no uso dos dados empíricos e na construção da teoria sociológica. Trata-se, portanto, de desmistificar Durkheim em nome da verdade científica, a qual exige uma representação fiel dos dados empíricos. Stoczkowski toma explicitamente o estudo controvertido de Daniel Dubuisson sobre Mircea Éliade (1993) como modelo. Defende uma concepção clássica da verdade científica, afastada de qualquer pós-modernismo - o que talvez torne a crítica dele mais dolorosa ainda para os durkheimólogos.

La Science sociale comme vision du monde está dividido em quatro partes: "O mundo segundo Durkheim, em que o autor, que procede à maneira do antropólogo, reconstituindo a cosmologia de um nativo, estabelece as grandes linhas da visão durkheimiana do mundo"; "À prova das coisas", sobre "o uso singular que Durkheim fazia dos dados fatuais para sustentar seus postulados"; "As (verdadeiras) regras do método, em que o leitor descobre os verdadeiros princípios do método durkheimiano e entende por 
que muitas vezes ele distorcia os fatos"; e, por fim, "Explicar e compreender, em que o autor explica o sistema cosmológico subjacente à teoria de Durkheim". Há certa redundância entre a primeira e a última parte, mas não a ponto de atrapalhar a leitura. A seguir, neste ensaio, acompanharei a progressão do livro, tecendo comentários acerca das críticas formuladas por Stoczkowski e de suas propostas epistemológicas.

\section{A cosmologia de um sociólogo decadentista}

A primeira parte resume a sociologia de Durkheim, de tal modo que caiba no esquema quaternário do autor. Para isso, Stoczkowski se apoiou nas quatro obras fundamentais do autor (De la division du travail social, 1893; Les Règles de la méthode sociologique, 1895; Le Suicide, 1897; Les Formes élémentaires de la vie religieuse, 1912), mas também nos cursos que ministrou nas Universidades de Bordeaux e Paris (L'Éducation morale, 1925; L'Évolution pédagogique en France, 1938; Pragmatisme et sociologie, 1955), na sua ampla correspondência com os colaboradores da Année sociologique, nas dezenas de artigos e centenas de resenhas que publicou na revista $e_{\text {, }}$ por fim, nos inúmeros textos, às vezes esquecidos, que saíram em revistas de filosofia (Revue philosophique de la France et de l'étranger, Revue de métaphysique et de morale, Bulletin de la société française de philosophie). O volume das referências examinadas pelo autor realmente impressiona, ainda mais pela sua diversidade.

Começando pela dimensão axiológica da cosmologia durkheimiana, esta, segundo Stoczkowski, transparece na distinção entre fatos normais e patológicos, que o próprio Durkheim considerava indispensável para a relevância da sociologia no mundo atual. "Nossas pesquisas não mereceriam uma hora de trabalho, se elas só tivessem um interesse apenas especulativo", disse Durkheim no prefácio de sua tese de doutorado (1991 [1893]:XXXIX). Contudo, tal distinção não apenas expressava uma preocupação reformista, conforme acreditam os durkheimólogos, mas "dissimulava" uma reflexão original sobre o mal (Stoczkowski 2019:47). Este não era intrínseco ao ato praticado, o que permitia definir certo nível de criminalidade como normal, algo que Tarde (1895) e Déploige (1911) nunca aceitaram. Conforme mostravam as recorrências dos conflitos nas relações de trabalho (lutas de classes) e a epidemia de suicídios anômicos, o verdadeiro mal se encontrava na insuficiência de integração (participação) e de regulação (controle), isto é, na exacerbação do egoísmo - "O homem fica menos apegado a si mesmo na medida em que se apega a si só" (Durkheim 1934 [1925]:59). 
Tal diagnóstico autoriza Stoczkowski a fazer de Durkheim um sociólogo da "decadência" (2019:56), sintonizado com os anseios que afligiam a geração fim-de-século. Esta sintonia geracional se manifesta no energetismo de Durkheim também, isto é, na atribuição de uma força específica aos fenômenos coletivos, como nos conceitos de "correntes suicidógenas" e de "efervescência social". Adiante, Stoczkowski lembra que, no final do século 19, o público culto assistiu atento à exploração científica das forças e energias que povoam o cosmos (forças gravitacionais, hidráulicas, térmicas, mecânicas, elétricas, vitais etc.). Ao mesmo tempo, essas forças constituíam "um reservatório de metáforas oportunas para pensar o homem, a história e a sociedade" (:256). Em particular, a moda do espiritismo fez com que as pessoas se interessassem "pelo estudo das 'forças psíquicas' e das 'energias mentais', que se manifestavam supostamente na prática da hipnose ou da transa" (:256). A eletricidade chamava a atenção, por estar presente no mundo tanto da matéria inerte quanto da vida - e Durkheim recorre à metáfora da eletrização para definir a efervescência coletiva.

Esse energetismo transparece ainda na neurastenia, doença inventada em 1869 pelo médico nova-iorquino George Miller Beard (também interessado nos usos terapêuticos da eletricidade), que interpretava os sintomas da depressão como esgotamento da "força nervosa". Tomava-se a atividade cerebral intensa como fator de neurastenia e o próprio Durkheim se achava neurastênico (Stoczkowski 2019:439). Stoczkowski nota que "o homem físico de Durkheim, com sua irritabilidade, sua inconstância, seu egoísmo, seus desejos insaciáveis, sua infelicidade e o mal do infinito do qual sofre, é o tipo do neurastênico, transposto sem grandes modificações do domínio médico para a sociologia" (:442). E para "tonificar, dinamizar, fortificar" o corpo doente da Sociedade, Durkheim preconizava "a influência 'dinamogênica' da efervescência coletiva" (Stoczkowski 2019:443).

Ainda que Stoczkowski não a aprofunde, a aproximação entre a sociologia durkheimiana, decadentismo, neurastenia e energetismo abre múltiplas possibilidades de interpretação. Até que ponto, por exemplo, a caracterização da anomia converge com os retratos da depressão executados pelos escritores decadentistas? Como não enxergar certa analogia entre a trajetória teórica de Durkheim e o itinerário ficcional do romancista JorisKarl Huysmans? A metamorfose do neurastênico des Esseintes, personagem decadente de À Rebours (1884), em Durtal, o protagonista de En Route (1895), que se converteu ao catolicismo por motivos estéticos depois de conviver com padres trapistas, condiz com a terapêutica durkheimiana do reencontro com a transcendência - porém, Durkheim sempre defendeu uma forma cívica e não divina de transcendência. 
Voltando-se para a ontologia de Durkheim, Stoczkowski distingue duas categorias fundamentais: os indivíduos e as sociedades humanas, já que Durkheim desconsiderava as entidades não humanas. Contudo, o sociólogo francês nunca intentou uma descrição empírica das relações entre indivíduo e sociedade, conforme os princípios elaborados nas Règles de la méthode sociologique. Em vez disso, repetiu a tese do homo duplex, muito comum entre os intelectuais de sua geração (Azouvi 1985). Estava o homem dividido em dois seres distintos: "um ser individual, que tem sua base no organismo e cujo círculo de ação encontra-se, por isso mesmo, estreitamente limitado, e um ser social que representa em nós a mais alta realidade, na ordem intelectual e moral, que nós possamos conhecer pela observação, ou seja, a sociedade" (Durkheim 1990 [1912]:23).

Quanto à origem histórica do mal que afeta as sociedades europeias, Durkheim a encontrou na decomposição da autoridade tradicional, principalmente cristã. Em L'évolution pédagogique, transcrição do curso que deu na Universidade de Bordeaux, Durkheim relê a história da "civilização" europeia com base nos marcos aprendidos nos manuais escolares da Terceira República. Elogia a solidariedade entre os judeus, cuja sociedade apresentava um grau relativamente baixo de evolução social. Expressa sua admiração pela Europa medieval, principalmente pelo período que o historiador JeanJacques Ampère chamou de "renascimento carolíngio" (séculos 8 e 9), na medida em que soube conciliar a moral com o individualismo. De fato, a descrição que Durkheim dá do ideal cristão se parece muito com a da moral em geral: "O ideal da vida cristã é o dever cumprido por ser o dever, é a regra aplicada por ser a regra; é o homem subindo em cima da natureza, se libertando dela, domando-a, submetendo-a às leis do espírito" (1938:47). Em contraposição, concebe o Renascimento como um período de egoísmo e crise moral. Por fim, como muitos outros (Joseph de Maistre, Alexis de Tocqueville, Jules Michelet), Durkheim faz da Revolução francesa o ponto culminante da história, marcado pelo declínio definitivo do cristianismo, sem que emergisse algum substituto. Em Le Socialisme, Durkheim trata a Revolução como o sintoma de uma crise moral, responsável pelo estado patológico das sociedades europeias, que persistiu ao longo do século 19.

Como solução à crise moral, Durkheim propõe a recriação das corporações, uma sugestão já formulada pelos reformadores católicos (Le Play 1864), e defende a instauração de uma moral laica, capaz de tomar o lugar da moral cristã. Em vez de Deus, esta nova moral deve se referir à Sociedade, a qual, na perspectiva de Durkheim, possui todos os atributos divinos, exceto seu caráter supernatural. "Entre Deus e a sociedade, é preciso escolher", disse Durkheim em um seminário de filosofia, "não examinarei 
aqui as razões que podem militar em favor de uma ou de outra solução; ambas são coerentes. Acrescento que, do meu ponto de vista, esta escolha me deixa indiferente, pois não vejo na divindade mais do que a sociedade transfigurada, e pensada simbolicamente" (1924:75). "Para se extrair do estado deletério de anomia", resume Stoczkowski, "a sociedade nova deve ser solidária como os judeus, moral como os cristãos, racional como o século" (2019:153). O papel da sociologia, nesta perspectiva, é de ajudar os homens a tomar conhecimento de suas necessidades morais. "O sociólogo durkheimiano não é o inventor de uma religião nova. É o anunciador, à semelhança dos profetas judaico-cristãos que não dispensavam um ensino pessoal, mas se limitavam em decifrar, esclarecer e espalhar as mensagens de Deus" (:151). Assim teríamos a nossa "promessa soteriológica".

\section{Clássicos vacilando}

Ao concluir a primeira parte, o leitor ainda não tem como entender os motivos da polêmica. Afinal, a cosmologia trazida à tona por Stoczkowski não diverge tanto das interpretações mais consensuais; aparece como uma entre várias interpretações possíveis. Já não é mais o caso na segunda parte, em que acusa Durkheim de "remodelar os dados para adaptá-los aos pressupostos de sua própria visão cosmológica" (:240). "A manipulação e a maquiagem dos dados disponíveis eram sistemáticas" (:178), afirma Stoczkowski, com base na sua análise meticulosa das fontes que Durkheim manuseou em Le Suicide e Les Formes élémentaires de la vie religieuse. "O gesto fundador da sociologia empírica consiste, paradoxalmente, em se livrar dos dados empíricos", sanciona o autor (:181).

Vale lembrar que Le Suicide está sendo alvo de críticas por parte de sociólogos, inclusive colaboradores de Durkheim, desde sua publicação. Em sua resenha publicada na Revue de métaphysique et de morale, François Simiand alertava sobre a mania que Durkheim tinha de transformar metáforas (as famosas "correntes suicidogêneas") em conceitos metafísicos (1898). Trinta anos depois, Maurice Halbwachs, outro companheiro da Année sociologique, releu a obra, criticou as fontes, incluiu novos aspectos (as tentativas de suicídio), ressaltou o peso dos fatores ecológicos (meio rural versus meio urbano) contra o fator religioso (1930). Em Social Meanings of Suicide (1967), Jack Douglas analisou o suicídio a partir das razões que os suicidas avançam para suas ações, contra o desprezo de Durkheim pelas explicações subjetivas. Houve recentemente uma reavaliação das leis que Durkheim deduzia de suas correlações estatísticas - na França 
contemporânea, são os moradores das regiões rurais que mostram as taxas mais elevadas de suicídio, em comparação com os moradores das grandes cidades (Baudelot \& Establet 2006). Stoczkowski, para além de seu próprio trabalho crítico, cita o estudo de Whitney Pope (1976), cujo balanço negativo foi muito mal recebido na França, e os artigos de Massimo Borlandi (2000, 2003), que também levantaram vários problemas na análise de Durkheim. A apresentação de Stoczkowski nem sempre faz justiça a esta longa tradição crítica. Em sua defesa, as introduções didáticas à obra de Durkheim nem sempre levam estas críticas em consideração, dando a falsa impressão de um clássico ainda intocado.

A novidade da leitura feita por Stoczkowski está na intepretação que dá às falhas no raciocínio de Durkheim: evidenciam o pouco apego que tinha pelos fatos empíricos. "Os dados estatísticos, para ele, longe de serem uma ferramenta de controle dos enunciados, são adotados como dispositivo retórico para produzir efeitos de persuasão" (2019:170). Importava a confirmação de uma correlação direta entre suicídio e falta de integração social, sendo que, de acordo com os preconceitos de seu tempo, Durkheim achava a prática protestante menos integradora do que a prática católica. Por isso, Durkheim ignorou certos dados, em particular os oriundos das províncias austro-húngaras, nas quais nem sempre os protestantes mostravam uma propensão ao suicídio maior do que os católicos. Também menosprezou outros fatores explicativos, evidenciados pela literatura suicidológica do século 19, como a miséria, a dor (em uma época em que se tinha pouco acesso aos analgésicos) e os dramas familiares - Durkheim não tinha como reconhecer este último, pois contradizia sua teoria (a família fazia parte das instituições integradoras).

O mesmo cinismo para com os dados empíricos se repetiu em Formes élémentaires. Aqui, mais uma vez, Stoczkowski não desbrava um solo virgem, mas nem sempre menciona as críticas anteriores, o que não se justifica, como no caso de Le Suicide, pois as Formes, especialmente na França, sempre foram o patinho feio da sociologia durkheimiana (Béra 2014b). Enquanto Le Suicide autonomizava a sociologia da filosofia, as Formes pareciam seguir o caminho inverso. "Aprenderemos pouco sobre religião nas Formes. Eis [um] livro para os historiadores da sociologia e os especialistas de Durkheim: esplêndido monumento, irremediavelmente datado e situado. Morto", afirmavam Christian Baudelot e Roger Establet em 1984 (:9). As resenhas que saíram logo após a publicação não pouparam Durkheim de avaliações negativas. Arnold Van Gennep, por exemplo, criticava o uso que Durkheim fazia de suas fontes: Native Tribes of Central Australia (1899) e Northern Tribes of Central Australia (1904), duas monografias sobre povos australianos 
redigidas por Walter Baldwin Spencer e Francis James Gillen. "Creio poder afirmar que seu valor teórico é menor do que o autor pensa; ele os trata como os comentaristas tratavam os textos sagrados, elucidando-os com muita erudição, mas sem perguntar se os três quartos dos materiais brutos eram dignos de confiança" (Van Gennep 1913:389). Tratava-se, segundo Van Gennep, de uma "etnografia livresca" (:389), uma apreciação retomada anos depois por Alfred Kroeber, que considerava datadas as obras de Durkheim e Mauss pela sua falta de contato com o campo (1935).

Antes de Aron, Van Gennep criticava também o "senso metafísico, mais ainda o senso escolástico" presente quando Durkheim fazia da sociedade "uma realidade natural; [que] por pouco ele diria cósmica" (1913:391). Ao contrário do que Stein sugere (2005:84), Malinowski também recebeu Formes com certo ceticismo, questionando a tentativa de construir uma teoria geral da religião a partir de apenas um caso etnográfico, a suposta universalidade da distinção entre o sagrado e o profano (desmentida em seguida por William Pickering, 1984) e a concepção da religião como oriunda da multidão (Malinowski 1913). "As vistas do professor Durkheim contêm inconsistências fundamentais", escrevia o antropólogo britânico (:529).

Assim como na sua interpretação de Le Suicide, Stoczkowski considera essas "inconsistências" metodológicas, empíricas e teóricas como a manifestação de um "projeto escondido" (dessein caché, Stoczkowski 2019:246). "Por um lado, a definição do fenômeno religioso, construída em torno da noção de sagrado, servia menos para distinguir o fato religioso, e mais para confundi-lo com a moral e os cultos laicos. Por outro lado, ela foi concebida não para dar conta das informações etnográficas sobre a 'religião' aborígene, mas para sustentar conjeturas de Durkheim sobre a 'religião' laica que devia nascer na Europa em breve" (246). As "inconsistências", uma vez realocadas no plano cosmológico, desaparecem. A universalidade da distinção entre o sagrado e o profano faz sentido na medida em que assegura a identidade entre a moral e a religião, que Durkheim considera indispensável para a salvação da humanidade europeia. Se Durkheim insiste na existência de uma divindade suprema entre os aborígenes, é por conta do axioma segundo o qual Deus não é nada mais do que a Sociedade transfigurada, axioma também necessário à sua soteriologia.

Se Stoczkowski convence ao mostrar como aparentes erros, omissões e extrapolações no raciocínio de Durkheim ganham sentido quando interpretados a partir de sua cosmologia, a atribuição de uma intenção escondida, manifestada na recorrência do verbo "dissimular", deixa o leitor perplexo. Em nenhum momento Stoczkowski comprova o caráter deliberado desta suposta dissimulação. Aliás, em outros trabalhos, Stoczkowski define as 
cosmologias como conjuntos de crenças ordinárias que não são reconhecidas enquanto crenças, por adotarem a roupagem dos saberes científicos (2015). Se as cosmologias não são crenças, mas axiomas para seus criadores, como acusá-los de contrabando epistemológico? A ocultação das cosmologias é o produto de uma ilusão ou de uma mentira? Se for o primeiro, não vejo como fazer desta ocultação um ato proposital, a menos que fosse por má fé. Eu não descarto, por parte de Stoczkowski, a imputação de uma má fé generalizada aos grandes teóricos das ciências sociais, mas tal imputação tem sua origem muito mais na cosmologia própria de Stoczkowski do que em provas concretas. Da mesma forma, se Stoczkowski considera que os grandes teóricos mentiram, tem que haver provas. Fica a hipótese das cosmologias como puras ilusões, ato não proposital, mas resta saber o porquê dessas ilusões - voltarei a este ponto na conclusão.

\section{A dissertação de filosofia: matriz do pensamento antropológico francês?}

Talvez a menos polêmica, a terceira parte de La Science sociale comme vision du monde me parece a mais interessante. Aqui, Stoczkowski deixa a análise interna para a compreensão do ecossistema intelectual dentro do qual Durkheim cresceu. Esta "etnologia histórica da cultura acadêmica francesa na época moderna" (2019:17) tem como objetivo identificar, através de Durkheim, a espécie do homo academicus gallicus (:15). Stoczkowski pressupõe, portanto, uma especificidade francesa na forma como Durkheim e outros cientistas sociais franceses pensam.

Stoczkowski começa pela propensão de Durkheim de perceber o mundo através de oposições binárias, que resolve pelo recurso a um raciocínio dialético - a despeito de sua ênfase na demonstração científica, Durkheim nunca parou de dialetizar. Por exemplo, quando discute no prólogo de Formes a origem das categorias que compõem nosso entendimento, Durkheim contrasta a tese empirista (categorias vindas da experiência) com a tese idealista (categorias anteriores à experiência) para chegar à sua tese, sociológica, de uma origem social das categorias. Tal oposição entre empirismo e idealismo se encontra em inúmeros escritos de Durkheim, mas, observa Stoczkowski, o sociólogo parece sempre preferir o idealismo ao empirismo - embora sociais, as categorias existem a priori. "O 'naturalismo sociológico' de Durkheim é, na verdade, um idealismo que se tornou supostamente empírico por intermédio da noção de Sociedade" (Stoczkowski 2019:320). Em outras palavras, a sociologia de Durkheim se aparenta com um idealismo transcendental que teria colocado a sociedade no lugar do sujeito. 
Para reconstituir as origens deste modo de pensar, Stoczkowski se debruça sobre um material original, até agora desconhecido: as dissertações de Durkheim no concurso da agrégation de filosofia de 1882. Desde sua criação pelo governo napoleônico em 1808, o concurso da agrégation serve para formar uma elite de professores no ensino público, sendo este notoriamente mais difícil do que o concurso comum - enquanto os primeiros são chamados de "agrégés", aqueles recrutados pela via comum são chamados hoje de "certifiés". Continua reinando sobre o concurso da agrégation de filosofia a dissertação, uma prova escrita, realizada em tempo limitado, sobre um assunto específico. Candidato ao concurso de 1882, Durkheim teve que se deparar com dois títulos diferentes: "Relações entre imaginação e pensamento" e "Exponham e avaliem a teoria moderna do evolucionismo". Não era a primeira vez que Durkheim tinha se prestado ao exercício da dissertação. Desde 1863, a dissertação de filosofia fazia parte das provas requeridas para a obtenção do baccalauréat, exame conclusivo do ensino médio, em que Durkheim passou em 1875 (em letras) e 1876 (em ciências). Entre 1876 e 1879, Durkheim prestou três vezes a prova do concurso para entrar na École Normale Supérieure, instituição pública de ensino superior que tinha a função de formar a elite dos professores até 1881, a École tinha o monopólio sobre a preparação para o concurso da agrégation. Para se tornar normalien, o domínio da dissertação era imprescindível.

Assim, por quase 10 anos, cruciais na sua formação, Durkheim praticou intensamente a dissertação. A dissertação continua desempenhando um papel fundamental na formação do homo academicus gallicus, especialmente em quem opta pelo ensino das letras e das ciências sociais (Tabela 1). Queria tomar como exemplo a minha própria trajetória, pois sou um dos nativos visados pela investigação de Stoczkowski. Entre 2001 e 2004, eu me preparei para as provas do baccalauréat économique et sociale na França, as quais incluíam uma dissertação de literatura, uma dissertação de ciências econômicas e sociais, uma dissertação de história ou geografia e uma dissertação de filosofia, de quatro horas cada uma. De 2004 a 2007, eu me preparei e prestei duas vezes a prova para o concurso de entrada na École normale supérieure. Assim como os outros 500 candidatos da minha sessão, tive que entregar uma dissertação de ciências econômicas e sociais, uma de literatura, uma de filosofia, uma de história e uma de alemão, em seis horas para cada uma, mais uma dissertação opcional de sociologia, em cinco horas. 
Tabela 1 - As questões no concurso da agrégation de 2020, por disciplina

\begin{tabular}{|l|l|}
\hline $\begin{array}{l}\text { Filosofia, sem programa*, } 7 \text { horas, } \\
\text { sem dossiê }\end{array}$ & O que aprendemos dos nossos afetos? \\
\hline $\begin{array}{l}\text { Filosofia, com programa, 7 horas, } \\
\text { sem dossiê }\end{array}$ & O que é uma representação bem-sucedida? \\
\hline $\begin{array}{l}\text { Ciências econômicas e sociais, } \\
\text { economia, 7 horas, sem dossiê }\end{array}$ & Regular os mercados da economia digital. \\
\hline $\begin{array}{l}\text { Ciências econômicas e sociais, } \\
\text { sociologia, 7 horas, sem dossiê }\end{array}$ & $\begin{array}{l}\text { A socialização é a construção social das } \\
\text { diferenças? }\end{array}$ \\
\hline $\begin{array}{l}\text { História, história antiga, } 7 \text { horas, } \\
\text { sem dossiê }\end{array}$ & Piedade e impiedade na religião pública. \\
\hline $\begin{array}{l}\text { História, história contemporânea, } \\
7 \text { horas, sem dossiê }\end{array}$ & Os anos 1968: cultura e contestação. \\
\hline $\begin{array}{l}\text { Geografia, geografia temática, } \\
7 \text { horas, sem dossiê }\end{array}$ & Turismo, lazeres e natureza. \\
\hline $\begin{array}{l}\text { Geografia, geografia dos territórios, } \\
7 \text { horas, sem dossiê }\end{array}$ & $\begin{array}{l}\text { Mutações da agricultura e dinâmica dos } \\
\text { espaços rurais na França. }\end{array}$ \\
\hline
\end{tabular}

Fonte: https://www.devenirenseignant.gouv.fr/cid148653/sujets-rapports-des-jurys-agregation-2020.html. *As provas de filosofia sem programa tratam de qualquer noção filosófica, enquanto as provas com programa tratam de um grupo de noções definido no edital do concurso.

Foi suficiente para mim, mas, entre 2007 e 2010, condiscípulos meus na École, que se tornaram cientistas sociais depois, passaram no concurso da agrégation de ciências sociais, depois de redigirem uma dissertação de ciências econômicas (7 h), uma de sociologia (7 h) e uma de história (6 h). Vale ressaltar que, ao lado das provas escritas, esses concursos compreendem o mesmo número de provas orais, as quais se resumem, na prática, a dissertações mais curtas. Há variações sutis entre as disciplinas: junto ao título da prova, vinha na dissertação de ciências econômicas e sociais um dossiê com documentos iconográficos, estatísticos e textuais para auxiliar o candidato; na prova de história, uma cronologia indicativa. Entretanto, a técnica retórica, minuciosamente descrita por Stoczkowski, não muda muito.

Quando se trata de dissertação, estamos falando, portanto, de uma prática central na formação de inúmeros cientistas sociais franceses. Só na equipe da Année sociologique, temos Durkheim, Paul Fauconnet, Célestin Bouglé, Henri Hubert, Robert Hertz, Maurice Halbwachs e François Simiand, todos normaliens e agrégés de philosophie, sendo Marcel Mauss agrégé de philosophie também e Henri Hubert normalien e agrégé d'histoire. Fora os durkheimianos, boa parte dos antropólogos franceses que deixaram sua marca na disciplina tiveram algum contato aprofundado com a dissertação. Lucien Lévy-Bruhl, Pierre Bourdieu, Maurice Godelier, Émmanuel Terray, Philippe Descola: todos são ou foram normaliens e agrégés de philosophie. 
Claude Lévi-Strauss, Jeanne Favret-Saada e Bruno Latour não prestaram o concurso para entrar na École normale, mas se tornaram agrégés de philosophie. Se tomarmos os três autores mais citados no campo das humanidades em 2007, Michel Foucault, Pierre Bourdieu e Jacques Derrida, os três são normaliens e agrégés de philosophie.

Ao voltar as suas atenções para a dissertação de filosofia e a agrégation, Stoczkowski não apenas exuma uma bizarrice do sistema de ensino superior francês. Contribui para aquilo que um colega meu, José Arruti, chamou, numa comunicação pessoal, de "antropologia das matrizes do pensamento antropológico". Se a "antropologia da antropologia", para retomar uma expressão que usava Mariza Peirano, não é nada nova, os antropólogos ainda dão pouca atenção para as práticas de escrita e os rituais acadêmicos com os quais precisam se acostumar antes de se tornarem antropólogos. Será que as modalidades mais comuns nas faculdades de língua inglesa do essay e do paper já preparam os antropólogos anglófonos para registrar sua presença no texto, apresentar seus dados empíricos e construir suas problemáticas de uma forma realmente peculiar (escrevendo esta linha, eu me dou conta do quanto a palavra "problemática" se deve à minha prática da dissertação...)?

A crítica da dissertação não é nova. Começou com... Durkheim, que publicou, em 1895, "L'enseignement philosophique et l'agrégation de philosophie" na Revue philosophique. Neste texto, o sociólogo já criticava a "ginástica" das classes de filosofia, que tornava os estudantes "indiferentes a tudo que é verdade objetiva, para os vincular mais ou menos exclusivamente à arte das construções e destruições dialéticas" (Durkheim 1895:128-129). Em vez de incentivar "a exatidão na análise e o rigor na prova, isto é, as qualidades que fazem o cientista e o filósofo", a ginástica da dissertação estimulava "o talento literário" (:129). Durkheim lamentava também a prevalência dos registros metafísico e místico nas argumentações dos alunos, duas das críticas que lhe foram feitas após a publicação das Formes! Stoczkowski, que cita o texto, está ciente do paradoxo. Aliás, uma vez concluída sua formação, Durkheim "se lançou na coleta de dados fatuais com o entusiasmo do neófito" (Stoczkowski 2019:333). Porém, ele não se deu conta de mais uma deformação normalienne: a redução de qualquer realidade a oposições binárias e simétricas, que supera uma síntese dialética. Este não escapou a Lévi-Strauss quando lembrou sua aprendizagem da filosofia na Sorbonne: "Comecei a aprender que qualquer problema, grave ou fútil, pode ser liquidado pela aplicação de um método, sempre idêntico, que consiste em opor dois pontos de vista tradicionais da questão; em introduzir o primeiro pelas justificações do senso comum, em seguida destruí-lo por meio do segundo; enfim, em rejeitá-los ambos, graças a um 
terceiro que revela o caráter igualmente parcial dos dois outros, reduzidos por artifícios de vocabulário aos aspectos complementares de uma mesma realidade" (1952:48).

Como raciocinava então Durkheim nas suas dissertações? Na sua prova sobre evolucionismo, de acordo com Stoczkowski, Durkheim tomou como ponto de partida não fatos empíricos, mas a oposição metafísica entre a unidade, associada ao espírito, e o múltiplo, associado à matéria. Na medida em que estabelece uma continuidade dentro de uma matéria aparentemente heterogênea, o evolucionismo fazia a síntese dialética entre a unidade e o múltiplo. Neste linguajar carregado de metafísica, sobrava pouco espaço para as teorias científicas da evolução, salvo algumas referências superficiais às obras de Darwin e Spencer - vale lembrar a crítica que Durkheim formulou em 1895: "A gente viu assuntos muito simples de psicologia ou de lógica [...] transformados pelas mãos de prestidigitadores hábeis demais em qualquer mediação de metafísica transcendental, sem relação com as questões colocadas, em que, na maioria do tempo, nenhum fato é citado" (1895:130131). Comentando as outras provas, Stoczkowski observa o mesmo desdém pelo conhecimento científico - significativamente, o candidato mais inteirado no assunto chegou em último lugar no concurso de 1881. Quase todos os candidatos deram razão a Kant contra o evolucionismo: para a maioria deles, a teoria darwiniana não era nada mais do que uma "doutrina" (Stoczkowski 2019:335). "As similitudes entre todas as provas são impressionantes", observa Stoczkowski, "os materiais conceituais usados, os procedimentos argumentativos aplicados e até as conclusões obtidas são de uma unidade extraordinária. É como se uma mão invisível tivesse guiado não apenas as canetas como o curso de suas reflexões" (:336).

Stoczkowski formula a hipótese de um "habitus dissertativo" ou "dialético" (:337, 416). Deste resultaria, em particular, "uma predileção pelas oposições binárias, pelas simetrias conceituais, pelas sínteses dialéticas" (:333), o que intrigou muito Stoczkowski. A preponderância do kantismo, com seu gosto pelas antinomias, no ensino da filosofia deve ter contribuído para tal predileção; o neokantismo de Charles Renouvier, filósofo importante na segunda metade do século 19, também - a categoria de pessoa, tão importante para os sociólogos da Année, mas ausente das tabelas aristotélica e kantiana, tinha sido destacada por Renouvier. Sem fazer referência a Hegel, filósofos cristãos e espiritualistas como Jules Lachelier e Émile Boirac já recomendavam um esquema ternário para a dissertação, pois ela devia chegar a uma conclusão que reconciliasse teses contraditórias ou adotasse uma posição média.

"A persistência das disposições normalistas, dissertativas, dialéticas" explicaria, portanto, a predileção de Durkheim por oposições simétricas 
(empirismo versus idealismo, por exemplo) e raciocínio ternário (superação pela sociologia). “O esquema ternário da dialética desempenhou na obra de Durkheim um papel mais importante que todos os preceitos epistemológicos detalhados nas Règles de la méthode sociologique" (Stoczkowski 2019:392). Até a escolha dos temas tratados pela sua sociologia obedecia à prática dissertativa. "Espanta descobrir que a quase totalidade dos temas constitutivos de sua sociologia, e também de sua cosmologia, pertencem ao repertório usado dos temas da dissertação de filosofia que a instituição escolar reservava na segunda metade do século XIX aos alunos de liceus, de classes preparatórias, da Escola Normal Superior, assim como aos candidatos da agrégation de filosofia" (:346). "A correspondência é tão precisa e completa que não seria excessivo encarar a sociologia durkheimiana como disciplina auxiliar da filosofia para escolas secundárias" (:347). Entretanto, este argumento não convence. O interesse de Durkheim pelo tema da criminalidade, por exemplo, parece muito mais ligado às preocupações que agitavam a ciência social de seu tempo, tratando-se de um assunto amplamente debatido por Tarde e pelos criminólogos italianos. Faltou listar as analogias entre os temas para realmente convencer o leitor de que a agenda da Année Sociologique coincidia com o programa oficial de filosofia.

Durkheim atualizava o habitus dissertativo quando rejeitava a experiência subjetiva como fonte de conhecimento, preferindo exemplos oriundos da literatura, das artes e da história clássica. Assim como na dissertação, os exemplos mobilizados por Durkheim em suas análises sociológicas servem para ilustrar e não demonstrar uma tese. "É a démarche típica da escrita dissertativa que se situa no registro da persuasão e não da prova" (Stockzkowski 2019:351). Da mesma forma, a preferência de Durkheim pelo racionalismo apriorista lembra sua formação filosófica, pois sempre defendeu o apriorismo de Kant e dos neokantianos contra o empirismo inglês - mas trata-se de um socioracionalismo, na medida em que coloca a Sociedade como fundamento da Razão, aí estaria a real novidade de Durkheim.

Stoczkowski vai além da forma dissertativa. Teria uma "tonalidade criacionista" (2019:363) no racionalismo que impregnou a formação filosófica de Durkheim. Assim, o candidato que chegou em primeiro lugar no concurso de 1882 rejeitava o evolucionismo em nome de uma finalidade transcendente, de natureza divina. É que o ensino da filosofia ficou fora do laicismo e do anticlericalismo, conforme se vê pelo perfil dos professores de filosofia da École normale: Jules Lachelier, Léon Ollé-Laprune, até Émile Boutroux, todos católicos e pensadores espiritualistas. "Longe dos clichês que dão ao ensino da Terceira República um radicalismo antirreligioso generalizado, 
Durkheim estudou em uma École Normale Supérieure que se parecia muito mais com um bastião do pensamento católico" (:366).

Existia, de fato, um consenso espiritualista entre os professores e os avaliadores de Durkheim (na banca de sua tese sobre a divisão do trabalho social tinha Charles-Pendrell Waddington, cofundador da Liga nacional contra o ateísmo em 1886). Faziam parte deste consenso as crenças na dualidade da natureza humana (alma versus corpo), na existência de um conhecimento independente da experiência (apriorismo) e na submissão necessária da vontade a imperativos morais - três teses que perpassam toda a obra de Durkheim. Assim, todos os candidatos na agrégation de filosofia de 1882 "repudiaram o materialismo, criticando seu monismo ontológico, sua causalidade mecânica, sua antropologia individualista, sua epistemologia empirista, sua moral utilitarista" (Stoczkowski 2019:372). Se, no seu primeiro livro, Durkheim parecia optar por uma abordagem pseudomaterialista (explicação da moral pela divisão social do trabalho), ele vai, ao longo da carreira, mudar para um quase espiritualismo (as forças religiosas como hipóstases das forças coletivas), em maior sintonia com o consenso filosófico da época - Stoczkowski sugere, com base em poucas evidências, que a defesa de Durkheim não transcorreu tão bem assim, pois a banca achou Durkheim materialista demais.

Ao relacionar, no caso de Durkheim, a prática da dissertação com a produção de ideias, acredito que Stoczkowski contribui de forma decisiva para esta "antropologia das matrizes do pensamento antropológico". Ainda que fuja do escopo definido pelo autor, sentimos a necessidade de perguntar se o ensino deste habitus dissertativo sobreviveu aos primórdios da Terceira República. O relato sarcástico de Lévi-Strauss sugere que sim. A escrita de Bourdieu, cheia de "deformações normaliennes", também. "De todas as oposições que dividem artificialmente a ciência social, a mais fundamental, e a mais perniciosa, é a que passa entre o subjetivismo e o objetivismo" (Bourdieu 1980a:24), afirmava ele no primeiro capítulo de Le Sens pratique, resumindo uma longa história de pequenas e grandes controvérsias epistemológicas a uma oposição simples, binária e simétrica. E, realmente, quantos artigos de Bourdieu não têm como ponto de partida esta mesma oposição (para conferir: 1979, 1980b, 1996, 2003), que ele se encarrega de superar dialeticamente graças à sua teoria da prática? E se a desconfiança de Bourdieu para com o material biográfico (1986) não traísse também a influência de um habitus dissertativo? 
Tudo indica, na verdade, que os defeitos enumerados por e em Durkheim aumentaram, a não ser a predileção pelo espiritualismo, que saiu de moda. Em um artigo publicado no dossiê "La dissertation" da revista Côté Philo, o historiador Bruno Poucet aponta para uma elitização da prática, já bem elitista, com a reforma do ensino de 1925 (Poncet 2006). Os professores de filosofia e os autores de manuais passaram a apresentar a dissertação de filosofia como um exercício espiritual, semelhante àqueles que praticavam os pensadores gregos, e o plano dialético em três partes se tornou uma exigência. A sociologia da filosofia também confirma a permanência do habitus dissertativo. Analisando as provas dadas no baccalauréat entre 1972 e 1996, Louis Pinto (2007) observa que: 1. os temas científicos (lógica, epistemologia das ciências exatas e sociais) ficam no segundo plano, 2. a tradição idealista (Platão, Descartes, Kant) continua predominante, 3. perguntas descontextualizadas ainda formam a base do exercício. Houve uma tentativa de reformar o ensino da filosofia em agosto de 2000, mas a proposta de incluir exercícios de argumentação se deparou com as reclamações de professores, segundo os quais a dissertação era "parte intrínseca do ato filosófico" (Poncet 2006:18).

Os filósofos Jean-Jacques Rosat (2006) e Pascal Engel (2006), no mesmo dossiê, aprofundaram o exame da dissertação enquanto instrumento cognitivo, sublinhando que, na dissertação filosófica, a unidade elementar do discurso não é a proposta, a tese ou o argumento, mas o conceito. A partir das noções presentes no título da prova, espera-se do candidato que faça variar os sentidos destas noções, de modo a introduzir progressivamente novos conceitos (daí as famosas transições de normaliens e agrégés de philosophie, que pulam da "filosofia da liberdade" para a "liberdade da filosofia" com base apenas no trocadilho). Com efeito, filósofos da autoprodução de conceitos, como Hegel, Nietszche ou Heidegger, se prestam muito melhor à dissertação do que filósofos analíticos, como Frege, Moore ou Quine. Aliás, eu, como estudante de filosofia no ensino secundário e na classe preparatória, só ouvi falar destes autores depois de passar no concurso da École normale.

Como sujeito nativo, tendo a concordar com as críticas da dissertação, com uma ressalva. Em primeiro lugar, existia realmente certo fetichismo da dissertação na classe preparatória. A boa dissertação tinha que ter três partes, mesmo que não seguisse uma progressão estritamente dialética. Para o meu professor de filosofia, não fazia sentido uma dissertação com apenas duas partes, porque todo ato de pensar comportava, por si só, três momentos. Era na disciplina de história que estranhava mais este formalismo, pois a minha professora recomendava a aplicação de um plano cronológico em três partes, eventualmente duas, para qualquer assunto - como se fosse sempre 
relevante dividir um objeto histórico em dois ou três períodos diferentes. Já nas disciplinas de ciências sociais ou de língua estrangeira, toleravam-se dissertações em duas partes, com uma progressão temática ou analítica. Ainda que, nas ciências sociais, línguas estrangeiras e história, algum dossiê estivesse à disposição dos candidatos, a dissertação nunca saía do registro retórico: tratava-se de discutir noções e, acessoriamente, fatos. Os fatos funcionavam como exemplos a serviço da discussão e não o inverso. Se bem que nem sempre os meus colegas mais hábeis na dissertação conseguissem se converter às exigências da pesquisa, que impõe outra relação com os fatos. Todavia, muitos dos meus colegas estavam cientes da artificialidade da dissertação e não consideravam o tipo de raciocínio privilegiado pelo exercício o único possível - e esses colegas costumavam se sair muito bem nas provas. Ainda assim, carecemos de pesquisas que avaliassem o grau de reflexividade entre os praticantes da dissertação.

A despeito de seu tom às vezes agressivo, não se pode menosprezar a importância do livro de Stoczkowski para a antropologia da antropologia francesa.

\section{Analogia formal e causalidade genética}

A última parte traz as teses mais polêmicas e frágeis. Em primeiro lugar, Stoczkowski afirma que a soteriologia de Durkheim, isto é, sua crença na salvação do mundo graças ao surgimento de uma moral laica, análoga à cristã, porém fundada na ciência social, deriva do cristianismo. A soteriologia durkheimiana seria uma "anamorfose da religião judaico-cristã enquanto doutrina da salvação", mas, "ao revestir a roupagem da ciência, dissimulava [...] suas raízes cristãs" (2019:449). O problema é que a crítica de Stoczkowski parte de um paralogismo. Na primeira parte, ele deixa muito claro que quer "estender o conceito de salvação para além de seu sentido teológico, sem reduzi-lo aos problemas tipicamente cristãos do pecado original e do destino da alma no além" (:30). Salvação se aplica, nesta perspectiva, a qualquer melhoramento do mundo. Pois bem. Se o projeto durkheimiano de transformação da sociedade pela moral laica aparece soteriológico em virtude de um conceito não teológico (não cristão) de salvação, então não há como deduzir o caráter teológico (cristão) deste projeto de sua ambição soteriológica. Tudo acontece como se o conceito de soteriologia variasse em extensão de acordo com as necessidades da argumentação: amplo no início para incluir o reformismo de Durkheim, restrito no final para convencer o leitor de que esse reformismo não passa, na verdade, de uma "transfiguração desnaturada da doutrina cristã" (:481). 
A menos que, para Stoczkowski, qualquer doutrina com a pretensão de melhorar o mundo seja uma anamorfose da soteriologia cristã? Atrás de qualquer pessoa querendo um mundo melhor se esconderia um "católico zumbi", para retomar a expressão polêmica de Emmanuel Todd (2015)? Tese ambiciosa. Stoczkowski tenta ser mais explícito.

O pensamento laico retomou, ao mesmo tempo em que as transformou e exacerbou, as duas ideias importantes do cristianismo. Primeiro, a de um mundo humano afetado pelos males que não estão ligados à natureza das coisas, mas gerados pelas vicissitudes da história. [...] A ideia do mundo que decaiu acidentalmente no mal se vê muitas vezes associada à crença de que a expulsão do mal do mundo - ou seja, a restauração de seu estado ideal - é possível. Ao herdar do cristianismo essas duas ideias, o pensamento moderno assegurou uma grande longevidade aos temas da Queda e da Salvação, ao mesmo tempo em que lhes conferia suas formas laicizadas e, aparentemente, racionais (Stoczkowski 2019:480).

O problema vem de uma definição larga demais do cristianismo. Se aceitarmos definir o cristianismo pela crença no caráter acidental do mal e na possibilidade de sua expulsão, logo vamos encontrar o cristianismo em todo e qualquer lugar. Segundo o meu professor de academia, o mundo se divide entre massa gorda e massa muscular (ontologia). A massa gorda faz mal à saúde, enquanto a massa muscular faz bem e torna a pessoa mais atraente (axiologia). A massa gorda resulta de maus hábitos, como o sedentarismo (etiologia). Para acabar com a massa gorda e alcançar o ideal de um corpo definido, é preciso malhar (soteriologia). Seria a retórica do meu professor de academia uma "transfiguração desnaturada da doutrina cristã"?

Há outro vício neste raciocínio: Como Stoczkowski passa de uma analogia formal (coincidência entre a forma da cosmologia durkheimiana e o cristianismo) a uma causalidade genética (a cosmologia durkheimiana como subproduto do cristianismo)? Faltou mostrar na biografia de Durkheim elementos que sustentassem essa influência do cristianismo nele. A menos que o simples fato de pertencer a uma sociedade cristianizada bastasse para deduzir essa causa? Só que, assim, qualquer criação cultural se torna uma anamorfose do cristianismo. A explicação perde, então, seu caráter discriminatório. Quando, já na conclusão, Stoczkowski afirma que "o cristianismo, enquanto religião da salvação, continua sendo para as ciências sociais tanto sua causa formal quanto sua causa final" (2019:501), resta saber por que se restringir às ciências sociais. "Mesmo quando critica o cristianismo, a civilização ocidental o faz por meio de conceitos herdados do cristianismo" (:501). Pois bem. O cristianismo parece funcionar na 
argumentação de Stoczkowski exatamente como o complexo de Édipo no freudismo ou a luta de classe no marxismo. Está em todo e qualquer lugar, mesmo quando não está. Tal procedimento argumentativo não parece condizer com o popperianismo implícito do autor.

Em seguida, Stoczkowski se aproxima perigosamente da reductio ad hitlerum. Volta às críticas de Durkheim contra as teorias pangermanistas do historiador antissemita Heinrich von Treitschke, com o qual o sociólogo francês compartilhava a mesma oposição entre o indivíduo e a sociedade, mas não a mesma representação do Estado. Esta divergência implicava a defesa de uma moral utilitarista e particularista do lado alemão, de uma moral fraterna e universalista do lado francês. Stoczkowski ressalta uma suposta incoerência no raciocínio de Durkheim, que concebe a moral coletiva como análoga à moral cristã, mas ao mesmo tempo reconhece o caráter evolutivo da moral coletiva. Se a moral muda igual a sociedade, como impedir o surgimento de uma moral violenta? Quais recursos sobram para os indivíduos se oporem a esta moral coletiva? Stoczkowski sugere que as ideias de Durkheim e outros "alquimistas modernos" (2019:479) prepararam o terreno para os massacres da Primeira Guerra Mundial e a instalação dos regimes totalitários (!). É que comunismo e nazismo "se esforçaram para realizar um ideal de vida social concebido como uma resposta aos medos da anomia, da astenia e da mediocridade moral, obsessões forjadas no século passado" (:467). Segundo Hitler, a crise que a Alemanha vivia nos anos 1920 era moral. Guerras e revoluções serviam para eletrizar as pessoas. As doutrinas nazistas e comunistas "se encontravam no seu jeito semelhante, de forma estranhamente durkheimiana, de conceber o indivíduo e suas relações com a sociedade" (:468).

Encontramos aqui o mesmo problema mencionado anteriormente: uma analogia formal, sem contornos nítidos, vira uma (suspeita de) causalidade genética. O próprio Stoczkowski reconhece que Durkheim nunca concebeu a sociedade como a negação do indivíduo, pelo contrário: uma moral adequada ao nosso tempo deve levar em consideração o processo de individualização. É justamente por isso que não podemos voltar à moral tradicional - e este ponto afasta Durkheim de qualquer conservadorismo revolucionário do tipo nazifascismo. É justamente por isso que uma sociedade inteiramente controlada pelo Estado não faz sentido.

Herdado do cristianismo, o sonho de um desaparecimento definitivo do mal se viu transferido do fim dos tempos para a extensão do mundo temporal. $\mathrm{O}$ homem moderno se tornou não apenas seu próprio Tentador, mas também seu próprio Redentor. Sua missão era renovar o mundo e depurá-lo definitivamente 
de suas falhas. [...] Aqueles que não se engajavam nesta transfiguração e que criavam obstáculos à revolução redentora deviam ser eliminados sem piedade, pois seu extermínio, supostamente necessário à abolição do mal, se tornava o instrumento do bem (Stoczkowski 2019:479).

O problema é que este tipo de escatologia não se encontra em Durkheim. Em nenhum momento a soteriologia durkheimiana, até na forma como Stoczkowski a apresenta, envolve a negação violenta do presente pelo futuro. Lutar para salvar ou melhorar o mundo não significa necessariamente querer sua negação violenta. É preciso distinguir entre várias modalidades de salvação, o que Stoczkowski não faz, o salvacionismo escatológico sendo apenas uma delas.

Ao criticar o jargão dos cientistas sociais, Stoczkowski afirma que "graças às noções de anomia, de estrutura, de capital simbólico, de redes de atores - sem falar da luta de classes ou do inconsciente -, cada coisa complicada pode receber uma interpretação simples" (:489). Só resta saber se "soteriologia" não mereceria entrar nesta lista.

\section{"Dançar em cima de um vulcão"}

Stoczkowski se despede do leitor com um final enigmático. "Seria prudente agora se iludir um pouco menos acerca da nossa racionalidade, da solidez dos nossos conhecimentos da coisa humana, da assistência que estes conhecimentos podem fornecer à nossa pressa de consertar o mundo. A fundação das ciências sociais não está atrás de nós: está na frente" (2019:503).

Fiquei então com a desagradável vontade de aplicar o esquema de Stoczkowski a ele próprio. Funcionaria mais ou menos assim. Segundo Stoczkowski, as ciências sociais estariam divididas entre propostas empiricamente comprovadas e anamorfoses de crenças ordinárias (ontologia). As primeiras, verdadeiras, participariam desse esforço coletivo chamado ciência; as segundas não, pois expressam visões pessoais do mundo, e se revelariam até perigosas (axiologia) - "as ideias têm consequências" (título do último capítulo). Teria como distinguir entre as duas até pelo jargão.

Palavras como "anomia", "efervescência", "coesão social", ou "estrutura", "bricolagem", "grupo de transformações", ou "capital simbólico", "campo social", "habitus", ou ainda "ator-rede", "cadeias de tradução", "não humanos" [...] oferecem ferramentas linguísticas prezadas muito mais pelo seu poder 
[...] de discorrer sobre todos os fenômenos em um idioma reconhecido como prestigioso do que pela sua capacidade de esclarecer realmente as coisas sobre as quais falamos (:490).

Resta saber como o conceito de "habitus dissertativo" conseguiu escapar desta tendência... Já a raiz do mal residiria no compartilhamento dessas crenças ordinárias (etiologia). A salvação das ciências sociais, isto é, sua verdadeira fundação, viria então de uma antropologia atenta à presença dessas crenças dentro das construções teóricas (soteriologia). Devo concluir que o livro de Stoczkowski não é nada mais do que uma "transfiguração desnaturada da doutrina cristã", ainda que aplicada ao mundo reduzido das ciências sociais... A serpente comeu o rabo.

Esse exercício não passa de retórico. Contudo, ele aponta, mais uma vez, para a necessidade de especificar melhor a noção de soteriologia, pois, na forma como se encontra, abrange até a argumentação de Stoczkowski. Além disso, cosmologias não são necessariamente um mal. Voltamos à hipótese inicial: "as ciências sociais produzem visões do mundo análogas às cosmologias estudadas pelos antropólogos nas sociedades não ocidentais" (2019:12). Então, por que não tratar as cosmologias das ciências exatamente como fazem hoje os antropólogos das sociedades não ocidentais? Hoje, nenhum antropólogo desqualificaria a cosmologia de um povo não ocidental porque não condiz com os preceitos de uma epistemologia mais ou menos popperiana.

Se as cosmologias não se resumem a "teratologias epistémicas" (Castro 2009:167), é porque não se confundem com conjuntos de propostas, similares àquelas que se encontram nos manuais de gramática, nem com representações mentais, conforme acredita o reducionismo cognitivista. Em L'Anti-Oedipe, Deleuze e Guattari defenderam que o mito "não é expressivo, mas condicionante" (1972:185). "O recurso ao mito é indispensável, não porque ele seria uma representação transposta ou até mesmo invertida das relações em extensão, mas porque só ele determina, conforme a prática nativa, as condições intensivas do sistema (inclusive do sistema de produção)" (:185). As "condições intensivas" remetem às singularidades que organizam nossa percepção concreta do mundo, às granulosidades do real que chamam a nossa atenção, às forças que deslocam nossa sensibilidade. "A intensidade é a forma da diferença como razão do sensível", ainda dizia Deleuze (1968:287). "É a intensidade que dramatiza. É ela que se expressa imediatamente nos dinamismos espaço-temporais de base" (:316). Ou seja, as cosmologias sempre são "cosmopraxis" (Castro 2009:166). 
Neste marco, a cosmologia de Durkheim aparece como condição para o surgimento de uma sensibilidade sociológica - ou seja, se as cosmologias são ilusões, trata-se de ilusões transcendentais, que possibilitam o exercício efetivo da razão sociológica. Ela é que distribuiu as singularidades a partir das quais Durkheim praticou a sociologia. Sem o seu desejo de corrigir os males de uma sociedade vista como decadente, talvez Durkheim nunca tivesse evidenciado novos tipos de suicídio, problematizado o processo de socialização na época moderna ou ressaltado o lugar das emoções na prática religiosa. A sua cosmologia carregou o mundo no qual Durkheim vivia de sentidos concretos, que sua prática científica explorava. A análise das cosmologias científicas não sai diminuída, pelo contrário: ela se torna parte de uma reflexão sobre as condições da percepção científica. Por isso também, o jargão que Stoczkowski tanto menospreza não se reduz a um jogo de linguagem, feito para agradar as instituições científicas. Ele transmite afetos e percepções. A palavra "anomia", por exemplo, não serve apenas para demonstrar fidelidade à Escola francesa de sociologia. Ela nos faz perceber novas dimensões da vida social, ela enriquece nossa intuição ou "apercepção sociológica", para falar como Louis Dumont (1979:20).

Claro que não podemos abraçar cosmologias sem cautelas críticas. Afinal, sempre serão visões parciais do mundo, mas eis a condição das ciências sociais: trabalhar a partir de e em meio a visões parciais do mundo. "Dançamos em cima de vulcões" (Deleuze 1968:301), que são nossas sensibilidades, com todas as suas insensatezes. E não poderia ser diferente, pois é a partir destas visões que criamos interesse pelo mundo, alimentando as nossas sensibilidades de cientistas sociais - vale dizer que, segundo a perspectiva que estou defendendo aqui, cosmologias não são reservadas aos "grandes teóricos", mas se encontram em cada produção das ciências sociais. A fundação das ciências sociais não está nem à frente, nem atrás. Ela se repete a cada instante, na provocação das nossas sensibilidades.

Recebido em 22 de setembro de 2020

Aprovado em 20 de fevereiro de 2021 
Thomas Jacques Cortado é Doutor em Antropologia Social pelo Museu Nacional (PPGAS/MN/UFRJ) e ex-aluno da Escola Normal Superior de Paris (ENS-Ulm). Está realizando o pós-doutorado na Universidade Estadual de Campinas (Unicamp) como bolsista da Fundação de Amparo à Pesquisa do Estado de São Paulo (Fapesp, processo 2018/12573-9). Faz parte do Núcleo de Estudos sobre Cultura e Economia (NuCEC), do Grupo Casa e do laboratório Urbano (IFCS/ UFRJ). Pesquisa processos de urbanização na fronteira das grandes metrópoles, em particular as interações entre práticas de autoconstrução, dinâmicas familiares, relações de propriedade e tecnologias de governo nos loteamentos periféricos do Rio de Janeiro.

https://orcid.org/0000-0003-2243-8735

E-mail: cortado.thomas@gmail.com

\section{Notas}

1 Enquanto este artigo já se encontrava no prelo, a revista Archives de sciences sociales des religions publicou, sob iniciativa de Matthieu Bréa, um dossiê sobre o livro de Stoczkowski, com três artigos de Marcel Fournier, Salvador Juan e Philippe Steiner (https://www-cairn-info.bsg-ezproxy.univ-paris3.fr/revue-archives-desciences-sociales-des-religions-2020-5.htm?contenu=sommaire). Durkheimólogo reconhecido, Steiner não esconde seu profundo aborrecimento.

2 Ao longo deste ensaio crítico, tiro proveito da minha experiência pessoal enquanto aluno do ensino médio francês (seconde générale, première e terminale économique et sociale entre 2001 e 2004) e de classe preparatória ao concurso da École Normale Supérieure (classe préparatoire B/L "Lettres et sciences sociales" entre 2004 e 2007, ano da minha aprovação). Assim, tento esclarecer pontos relacionado à recepção de Durkheim na França e à prática da dissertação. Sinalizo também que assisti ao seminário de Wiktor Stoczkowski durante o meu mestrado na EHESS, entre 2008 e 2012. 


\section{Referências bibliográficas}

ARON, Raymond. 1967. Les étapes de la pensée sociologique. Paris: Gallimard.

AZOUVI, François. 1985. "Homo duplex". Gesnerus: Swiss Journal of the history of medicine and sciences, $42(3-4): 229-244$.

BAUDELOT, Christian \& ESTABLET, Roger. 1984. Durkheim et le suicide. Paris: PUF. . 2006. Suicide. L'envers de notre monde. Paris: Le Seuil.

BÉRA, Matthieu. 2014a. "Durkheim en débat: La critique de Durkheim dans quelques ouvrages d'introduction à la sociologie". Idées économiques et sociales, 178:45-55.

. 2014b. "Les traitement des Formes élémentaires dans les manuels de sociologie: de l'occultation aux rejets". Cahiers de recherche sociologique, 56:13-32. . 2019. "Le Durkheim de Stoczkowski". Bulletin d'histoire de la sociologie, (10):8-9.

BORLANDI, Massimo. 2000. "Lire ce que Durkheim a lu. Enquête sur les sources statistiques et médicales du Suicide". In: M. Borlandi \& M. Cherkaoui (orgs.), Le suicide, un siècle après durkheim. Paris: PUF. pp. 9-46.

. 2003. "De Morselli à Durkheim (et retour): contribution à l'histoire de la sociologie du suicide". Genève: Droz. pp. 33- 55.

BOURDIEU, Pierre. 1979. "Le paradoxe du sociologue". Sociologie et sociétés, 1 (85):94.

. 1980a. Le Sens pratique. Paris: Éditions de Minuit. . 1980b. "L'identité et la représentation: éléments pour une réflexion critique sur l'idée de région". Actes de la recherche en sciences sociales, 35:6372.

. 1986. "L'illusion biographique". Actes de la recherche en sciences sociales, 62-63:69-72. . 1996. "La double vérité du travail". Actes de la recherche en sciences sociales, 114:89-90.

. 2003. "L'objectivation participante". Actes de la recherche en sciences sociales, 150:43-58.

CASTRO, Eduardo Viveiros de. 2009. Métaphysiques cannibales. Paris: PUF.

DELEUZE, Gilles. 1968. Différence et répétition. Paris: PUF.

DELEUZE, Gilles \& GUATTARI, Félix. 1972. L'Anti-Oedipe. Paris: Éditions de minuit.

DÉPLOIGE, Simon. 1911. Le conflit de la morale et de la sociologie. Paris: Nouvelle Libraire Nationale.

DOUGLAS, Jack. 1967. Social Meanings of Suicide. Princeton: Princeton University Press.

DUBUISSON, Daniel. 1993. Mythologies $d u$ XXe siècle. Lille: Presses Universitaires de Lille.

DUMONT, Louis. 1979. Homo hierarchicus. Paris: Gallimard.

D URKHEIM， Émile. 1895 . "L'enseignement philosophique et l'agrégation de philosophie". Revue philosophique de la France et de l'étranger, 40:606-623. . 1990 [1912]. Les Formes élémentaires de la vie religieuse. Paris: PUF. - 1924. Sociologie et philosophie. Paris: Félix Alcan. . 1934 [1925]. L'éducation morale. Paris: PUF. . 1938. L'évolution pédagogique en France. Paris: Félix Alcan. 
ENGEL, Pascal. 2006. "Y a-t-il une vie après la dissertation ?". Côté Philo, 9:23-29.

GENNEP, Arnold van. 1913 . "Ethnographie, folklore". Revue de la Quinzaine, 16 de janeiro. pp. 389-391.

HALBWACHS, Maurice. 1930. Les Causes du suicide. Paris: Félix Alcan.

LAMY, Jérôme \& ARNAUD, Saint-Martin. 2020. "Salut à toi, Durkheim!". Zilsel, 7:492-516.

LE PLAY, Frédéric. 1864. La réforme sociale en France. Paris: Henri Plon.

MALINOWSKI, Bronislaw. 1913. "Reviews: Les Formes élémentaires de la vie religieuse". Folklore, 24 (4):525-531.

MONNEROT, Jules. 1946. Les Faits sociaux ne sont pas des choses. Paris: Gallimard.

NIZAN, Paul. 1965 [1932]. Les Chiens de garde. Paris: François Maspero.

PÉGUY, Charles. 1992 [1905]. "Heureux les systématiques". CEuvres complètes. Tome 2. Paris: Gallimard. pp. 281-283.

PIAGET, Jean. 1955. Études sociologiques. Genève: Droz.

PINTO, Louis. 2007. La vocation et le métier de philosophe. Paris: Seuil.

POPE, Whitney. 1976. Durkheim's Suicide. A classic analyzed. Chicago: The University of Chicago Press.

POUCET, Bruno. 2006. "Histoire de la dissertation de philosophie dans l'enseignement secondaire". Côté Philo, 9:5-22.
ROSAT, Jean-Jacques. 2006. "Penser et disserter". Côté Philo, 9:23-29.

SIMIAND, François. 1898. "L'Année sociologique 1987". Revue de métaphysique et de morale:608-653.

SOREL, Georges. 1895. "Les théories de M. Durkheim". Le devenir social, 1:1-26.

STOCZKOWSKI, Wiktor. 1993. "La préhistoire: les origines du concept". Bulletin de la Société préhistorique française, 90 (1):13-21. 1999. Des hommes, des Dieux et des extraterrestres. Paris: Flammarion. . 2000. Anthropologie naïve, Anthropologie savante. Paris: Éditions du CNRS. . 2008. Anthropologies rédemptrices. Paris: Hermann. .2015. "Les sciences sociales ont-elles peur de l'ordinaire? La connaissance ordinaire et la fascination pour l'extraordinaire". La distinction des savoirs. Paris: Éditions de l'EHESS. pp. 157-177. . 2019. La science sociale comme vision du monde. Paris: Gallimard.

TARDE, Gabriel. 1895. "Criminalité et santé sociale". Revue philosophique de la France et de l'étranger, 39:148162.

TODD, Emmanuel. 2015. Qui est Charlie ? Paris: Seuil.

VARGAS, Eduardo et al. 2014. "O debate entre Tarde e Durkheim". Teoria e Sociedade, Esp.:28-61. 
CONTRA DURKHEIM. LA SCIENCE

SOCIALE COMME VISION DU

MONDE, DE WIKTOR STOCZKOWSKI
AGAINST DURKHEIM . LA SCIENCE

SOCIALE COMME VISION DU

MONDE, BY WIKTOR STOCZKOWSKI
Resumo

Este artigo discute o polêmico livro do professor Wiktor Stoczkowski, La Science sociale comme vision $d u$ monde, publicado em 2019. Com o subtítulo Émile Durkheim et le mirage du salut, o livro acusa Durkheim de maquiar os dados empíricos, distorcer as interpretações de suas fontes e reproduzir os clichês filosóficos de seu tempo para promover uma visão pessoal do mundo, uma "cosmologia". Tal visão, porque pretende salvar a humanidade dos males modernos, aproximar-se-ia perigosamente dos messianismos totalitários. Ao mesmo tempo em que expõe os principais argumentos de Stoczkowski, este ensaio ressalta a relevância do livro para uma "antropologia das matrizes do pensamento antropológico", assim como critica vários de seus pressupostos. Em conclusão, esboça outra concepção de possível relação entre ciência e cosmologia pessoal que enfatize o lugar da imaginação teórica na pesquisa.

Palavras-chave: Durkheim, Stoczkowski, Cosmologia, Epistemologia, Imaginação.
Abstract

This article discusses the controversial book by Professor Wiktor Stoczkowski, La Science sociale comme vision du monde, published in 2019. Also called Émile Durkheim et le mirage du salut, Stoczkowski's book accuses Durkheim of cheating, distorting the interpretations of other social scientists, and reproducing the philosophical clichés of his time in order to promote his own view of the world, his "cosmology". Since it seeks to save humanity from the evils of the contemporary world, this view would come dangerously close to those of totalitarian messianisms. While it exposes Stoczkowski's main arguments, this essay highlights the relevance of the book for an "anthropology of anthropological thought's matrixes". It also criticizes several of its assumptions. In brief, this essay outlines another possible conception for the relation between science and personal cosmology, one which emphasizes the importance of theoretical imagination in scientific research.

Keywords: Durkheim, Stoczkowski, Cosmology, Epistemology, Imagination. 


\section{CONTRA DURKHEIM . LA SCIENCE}

\section{SOCIALE COMME VISION DU}

MONDE, DE WIKTOR STOCZKOWSKI

\section{Resumen}

Este artigo analiza el controvertido libro del profesor Wiktor Stoczkowski, La Science sociale comme vision du monde, publicado en 2019. Con el subtítulo Émile Durkheim et le mirage du salut, el libro acusa a Durkheim de inventar sus datos empíricos, distorsionar las interpretaciones de sus fuentes y reproducir los clichés filosóficos de su tiempo, para promover una visión personal del mundo, una "cosmología". Tal visión, que pretende salvar a la humanidad de los males modernos, se acercaría peligrosamente a los mesianismos totalitarios. Al mismo tiempo que expone los principales argumentos de Stoczkowski, este ensayo destaca la relevancia del libro para una "antropología de las matrices del pensamiento antropológico", además de criticar varios de sus supuestos. En conclusión, esboza otra posible concepción de la relación entre ciencia y cosmología personal, que enfatiza el lugar de la imaginación teórica en la investigación.

Palabras clave: Durkheim, Stoczkowski, Cosmología, Epistemología, Imaginación. 